\title{
REFLEXÕES TEÓRICAS SOBRE JUSTIÇA INTERNACIONAL: REVISITANDO HEDLEY BULL
}

\section{THEORETICAL REFLECTIONS ON INTERNATIONAL JUSTICE: FACING HEDLEY BULL}

\begin{abstract}
Ana Paula Tostes
Pós doutora em Ciência Política pela Universidade de São Paulo (USP), Doutorado em Ciência Política pelo IUPERJ (atual IESP/UERJ). Professora do Departamento de Relações Internacionais da Universidade do Estado do Rio de

Janeiro (UERJ).

aptostes3@gmail.com

MarCelo Mello Valença

Professor adjunto do Departamento de Relações Internacionais e do Programa de Pós-Graduação em Relações Internacionais da Universidade do Estado do Rio de Janeiro (PPGRI/UERJ). Doutor em Relações Internacionais pela

PUC-Rio.

marcelo.valenca@gmail.com
\end{abstract}

\section{RESUMO}

O artigo tem o objetivo de apresentar uma reflexão sobre a influência do racionalismo grociano no debate sobre justiça internacional. 0 desafio da realização de uma justiça comum entre atores estatais soberanos perpassa debates clássicos da história e da teoria da constituição da sociedade internacional no período pós-guerra. Trata-se de uma pesquisa teórica que visa aprofundar o debate sobre justiça e apresentar um diálogo entre autores de diferentes campos de estudo que não têm sido confrontados em um ambiente interdisciplinar que permita o aprofundamento de conceitos de justiça para pesquisadores de temas jurídicos e políticos internacionais. 0 argumento do artigo é que a contribuição teórica de Hedley Bull, ao enfrentar as possíveis contradições entre os valores da ordem e da justiça no contexto da anarquia internacional, corrobora com o debate sobre os conceitos e limites de uma justiça internacional. O artigo está dividido em três partes. A primeira parte foca no enquadramento da reflexão de Bull em relação aos debates sobre teoria da justiça. A segunda parte traz a reflexão sobre a subjetividade da justiça internacional. A terceira parte apresenta os problemas conceituais de justiça sob o prisma do argumento da relatividade das prioridades e metas a serem alcançadas. A conclusão orienta a reflexão final sobre a relevância da contribuição de uma perspectiva racional que busca conciliar a prevalência da igualdade jurídica e soberania dos atores estatais com a possível ameaça da ordem. Ficando inconclusa a exploração do tema, pela sua própria natureza, o artigo busca contribuir para uma visão interdisciplinar sobre a combinação das características de sociedade e de anarquia da ordem internacional, ao mesmo tempo, e as vantagens de uma ordem mínima, sob o ponto de vista racional.

Palavras-chave: Hedley Bull; justiça internacional; sociedade anárquica, teoria da justiça.

\begin{abstract}
The article aims to introduce a reflection on the impact of Grotian rationalism in the debate on international justice. The challenge of achieving a common justice among sovereign states permeates classical debates of history and theories about the constitution of international society in the post-war period. This is a theoretical research that seeks to deepen the debate on justice and introduce a dialogue between authors from different fields of study that have not been confronted in an interdisciplinary environment that allows the deepening of concepts of justice for researchers of international legal and political topics. The main argument is that the theoretical contribution of Hedley Bull, to face the possible contradictions between order and justice values in the international anarchy, contributes to the debate on the concepts and limits of an international justice. The article is divided into three parts. The first part focuses on the combination of Bull's reflections with the theoretical debates about justice. The second part presents a consideration on the subjectivity of international justice. The third part stretches the conceptual problems of justice under the relativity argument prism of priorities and goals to be achieved. The conclusion guides the final consideration on the importance of the contribution of a rational perspective that seeks to merge the prevalence of legal equality and sovereignty of states with the possible threat of the order. Getting unfinished the subject of exploitation by its very nature, the article seeks to contribute to a interdisciplinary insight into the arrangement of the characteristics of society and anarchy of the international order at the same time, and the advantages of a minimum order under the rational point of view.
\end{abstract}

Keywords: Hedley Bull; international justice; anarchical society, theory of justice. 


\section{SUMÁRIO}

INTRODUÇAO; 1. ANTECEDENTES E CORRENTES; 2. UMA JUSTIÇA INTERNACIONAL PARA QUEM?; 3.BULL: ORDEM VERSUS JUSTIÇA NA POLÍTICA INTERNACIONAL; CONCLUSÃO; REFERÊNCIAS.

\section{INTRODUÇÃO}

“As idéias da justiça mundial ou cosmopolita só são realizáveis (se o são) no contexto de uma sociedade mundial ou cosmopolita. Portanto, as demandas para uma justiça mundial são inerentemente revolucionárias e implicam uma transformação do sistema e da sociedade de Estados"

(Hedley Bull, Sociedade Anárquica, p. 104)

$\mathrm{Na}$ transição para a modernidade, a quebra do universalismo ético, político e epistemológico, levou à criação de várias esferas de atuação e de interpretação da atuação humana. Assim, o mundo moderno se caracterizou por inaugurar uma independência procedimental da esfera do direito em relação à dimensão ética, assim como da política em relação à religião e à moral. Neste contexto de mudanças, tema árduo se torna o da justiça internacional. Transladando-se princípios e pressupostos de caráter valorativo ou concepções de direitos naturais, para as relações entre Estados, o debate sobre justiça internacional pode representar uma aceitação de uma possível reunificação de aspectos morais ou éticos à política, assumindo-se assim seus benefícios e também conhecidos riscos para a paz e a ordem em um mundo diverso em que o pluralismo cada vez mais se impõe. Dito isto, pode-se reconhecer que uma justiça internacional que leve em conta valores sociais e democráticos encontra ao menos dois impasses. Primeiro, o inconcluso debate sobre o marco normativo de uma noção inconteste de "justiça internacional global". Segundo, a dificuldade em se efetivar meios de enforcement para os atores na condição da ação internacional. Este artigo não trata do tema da universalidade de direitos ou de justiça, mas pretende fazer uma excursão histórica do argumento sobre os pressupostos e sobre o impacto da noção de justiça internacional, desde o contexto do pensamento clássico. 
Ao propor uma obra que discorra e analise a ordem internacional, Hedley Bull ${ }^{1}$ considera um caminho possível e razoável entre a insegurança da anarquia e a utopia de uma comunidade cosmopolita. No seio de sua contribuição histórica e teórica sobre uma ordem internacional possível após a segunda guerra, Bull enfrenta o tema da justiça internacional e esclarece ponto fundamentais para a compreensão dos debates que seguem existindo até atualmente. No contexto da obra sobre "ordem", o autor parte de uma visão grociana da ordem internacional para desvelar os riscos em se considerar a justiça como meta fundamental, quando se trata do contexto das relações entre Estados soberanos e juridicamente autônomos. Tendo em mente a estabilização da ordem internacional, valores mínimos compartilhados e instituições comuns constituem uma dinâmica objetiva de interação social, mas nem por isso se confundem com a perspectiva da realização da justiça como meta. Ao contrário da objetividade que se pode atribuir à ordem - mesmo enquanto um valor, "a justiça é um termo que só podemos definir em última instância, de modo pessoal e subjetivo." 2 Assim, o próprio conceito varia entre uma noção de "virtude" e "moralidade" ou de "remoção de privilégios ou discriminação, para a igualdade da distribuição ou aplicação de direitos entre os fortes e os fracos, os grandes e os pequenos, os ricos e os pobres, (...).”3 Essa variação e subjetividade implica que a aplicação da justiça, ao invés de corroborar para a ordem, pode resultar em desordem e revolução. Isso porque a prevalência das diferenças de concepção de justiça, que sempre implicam uma convicção moral, precisaria entrar em disputa para uma solução vencedora de visão de mundo.

Em suma, a contribuição teórica de Hedley Bull, ao enfrentar as possíveis contradições entre os valores da ordem e da justiça no contexto da anarquia internacional, corrobora com o debate sobre os conceitos e limites de uma justiça internacional. Este artigo é fruto de uma pesquisa teórica que visa aprofundar o debate sobre justiça e apresentar um diálogo entre autores de diferentes campos de estudo que não têm sido confrontados em um ambiente interdisciplinar que permita o aprofundamento de conceitos de justiça para pesquisadores de temas jurídicos e políticos internacionais. $\mathrm{O}$ artigo está dividido em três partes. A primeira parte foca no enquadramento da reflexão de Bull em relação aos debates sobre teoria da justiça. A segunda parte traz a reflexão sobre a subjetividade da justiça internacional. A terceira parte apresenta os problemas conceituais de justiça sob o prisma do argumento da relatividade das

\footnotetext{
${ }^{1}$ Obra originalmente publicada em 1977, é usada nesse artigo a seguinte edição: BULL, Hedley. Sociedade Anárquica, São Paulo: Ed. Unb-IPRI, 2002.

${ }^{2}$ BULL, Hedley. Sociedade Anárquica, São Paulo: Ed. Unb-IPRI, 2002, p. 92.

${ }^{3}$ Ibidem. p. 114.
} 
prioridades e metas a serem alcançadas. A conclusão orienta a reflexão final sobre a relevância da contribuição de uma perspectiva racional que busca conciliar a prevalência da igualdade jurídica e soberania dos atores estatais com a possível ameaça da ordem.

\section{DEBATES ANTECEDENTES E CORRENTES}

Distinções entre a definição de "justiça" que aparecem em obras de John Rawls ( $A$ Theory of Justice, 1971) e Morris Ginsberg (On Justice in Society, 1965) tem sido objeto de controvérsia nos debates sobre a possibilidade de se constituir uma justiça internacional. Rawls, um dos mais conhecidos expoentes da teoria da justiça internacional, procura dissecar o tema da justiça distributiva, pois o autor considera a desigualdade mundial como um problema fundamental do ponto de vista normativo. Assim como Thomas Hobbes, John Locke, e JeanJacques Rousseau, John Rawls pertence à tradição contratualista. No entanto, o papel e os limites do contrato social nas diferentes teses contratualistas que surgiram na história do pensamento político são bastante diferentes. O contrato social se diferencia pelos modelos de acordos que geraram, pela disposição dos atores em honrá-lo e, principalmente, pelas razões de sua sustentação. Além disso, teses de contrato social buscam explicar a realidade contemporânea seja para legitimá-la (como o fez Locke sobre o modelo inglês do século XVII) ou produzir uma crítica sobre a realidade (como é o caso de Rousseau), na defesa de uma reformulação do contrato e na expectativa da transformação radical das instituições sociais.

Desde a publicação de importantes contribuições ao debate, como as de Charles Beitz (Political Theory and International Relations, primeira edição publicada em 1979) e Thomas Pogge (Realizing Rawls, 1989), a literatura de teoria política sobre o tema da justiça em um contexto internacional ganha corpo rapidamente. Não apenas pela relevância do tema, mas também pela associação com o debate da democracia nas relações internacionais. ${ }^{4}$ Entretanto, segue controversa a questão de se a pobreza e as desigualdades globais devem de fato ser consideradas sob a ótica de uma noção de justiça ou de equilíbrio de poder. Como observou Philippe Van Parijs, "a questão decisiva é a de saber se há características que distinguem o

${ }^{4}$ VILLA, Rafael \& TOSTES, Ana Paula. Democracia Cosmopolita versus Política Internacional. Lua Nova. v. 66, 2006, pp. 66-107 
âmbito doméstico do global tão decisivamente a ponto de que, embora a justiça distributiva igualitária seja apropriada para o primeiro, não o é para o segundo". ${ }^{5}$

Fazendo-se um retorno ao pensamento filosófico clássico da política moderna, de acordo com uma perspectiva hobbesiana, o equilíbrio possível existente entre indivíduos em uma situação pré-civil e pré-contratual, não se daria pelo compartilhamento de uma consciência sobre direitos alheios nem se explicaria por razões normativas ou de justiça, mas, sim, por estratégias de força, interesse e equilíbrio de poder. Da mesma forma, segundo a perspectiva realista das Relações Internacionais, na medida em que não há condição originária ética entre atores que não são naturalmente sociáveis, mas sim auto interessados, mesmo a existência de instituições de governança e regulação, pode ser interpretada como fruto de interesse das potências dominantes. Assim, restrições a comportamentos estratégicos baseadas em pressupostos éticos ou de justiça, só se aplicariam às relações domésticas, ou seja, entre o Estado e seus cidadãos - onde se pressupõe uma homogeneização de valores e uma hierarquia organizacional para controlar as preferências mais gerais. Está implícito neste caso uma concepção de razão como cálculo, razão estratégica para a qual fins sempre justificam meios no universo da política, por pressupor uma ética da eficácia em que a ação política é teleológica. Para este modelo de entendimento, o meio internacional seria melhor interpretado como uma anarquia, nas condições do estado de natureza hobbesiano, em que o direito natural à liberdade poderia ser comparado à tendência expansionista dos Estados e o direito à igualdade comparado à regra da igualdade soberana estabelecida nos acordos de Paz de Westphalia, no século XVII. ${ }^{6}$ Em outras palavras, só seria possível imaginar-se uma igualdade formal sem nenhuma menção a valores de justiça ou igualdade material. Finalmente para o realismo político, pode-se dizer que o sistema internacional se constituiu por acordos de respeito à autonomia e expectativa de reciprocidade entre Estados, mais do que pela existência de um ethos societário internacional.

Diferentemente, o modelo contratualista lockeano serve melhor a uma leitura liberal das relações entre Estados em que, mesmo em uma situação de falta de um governo central, é

\footnotetext{
${ }^{5}$ PARIJS, Philippe Van. International Distributive Justice. In: GOODIN, Robert E.; PETTIT, Philip; POGGE, Thomas (orgs), A Companion to Contemporary Theory, vol. 2. Oxford: Blackwell, 2007, pp. 639; KAPSTEIN, Ethan. Distributive Justice as an International Public Good. In: KAUL, Inge; GRUNBERG, Isabelle; STERN, Marc A. (eds). Global Public Goods, Oxford: UNDP-Oxford University Press, 1999, pp. 88115.

${ }^{6}$ OSIANDER, Andreas. Sovereignty, International Relations, and the Westphalian Myth. International Organization. n. 55, v. 2, 2001, p. 251-287.
} 
possível se constituir instituições comuns que refletem expectativas compartilhadas na regulação de comportamentos, ainda que se mantenha a soberania e a liberdade individual das unidades sociais, no caso os Estados, é possível imaginar-se uma noção de justiça ou moral compartilhada. Inspirado pelo racionalismo grociano, Bull apresenta uma visão solidarista das relações entre os Estados, no sentido de que há elementos de respeitabilidade recíproca e da existência de uma lei natural mesmo sem consentimento ou contrato social entre Estados. Esta ordem social, no entanto, não se confunde com uma noção de justiça como o que se entende sobre justiça no ambiente da política doméstica de uma estrutura democrática.

No contexto das reflexões de representantes da Escola Inglesa, tantas vezes em competição e conflito, a "sociabilidade" dos Estados e a ausência do egoísmo exacerbado dos atores estatais se confirma em qualquer abordagem que contempla a possibilidade da sociedade internacional, foca na prevalência da paz sobre a guerra nas Relações Internacionais e se mantém crédula em relação ao possível aperfeiçoamento da ordem internacional.

Hurrell $^{7}$ destaca os elementos de proximidade e distanciamento do pensamento de Bull com as principais abordagens teóricas das relações internacionais. Dentre as importantes associações que faz o autor, é possível destacar o quanto as instituições concebidas por Bull são elementos do realismo e importante destaque deve ser dado ao equilíbrio de poder como elemento central da tese da sociedade internacional do autor, dos mais lidos dentre os demais representantes da Escola Inglesa. Sem o equilíbrio de poder e sem o entendimento compartilhado entre grandes potências ao conduzirem as relações internacionais, “'softer' elements of international order (international law, international organisations, the existence of shared values) would be so many castles in the air.". ${ }^{8}$ Portanto, é certo dizer que a institucionalização internacional já deve ser interpretada como um estágio de aperfeiçoamento da ordem internacional e sua progressiva transformação em um espaço de acordos críveis e expectativas de cooperação. Mas quais seriam os limites desse aperfeiçoamento, no sentido de se excluir, como faz Bull, a construção de uma justiça internacional como fruto da continuidade da organização, regulação, institucionalização e aperfeiçoamento da ordem. A constituição de uma justiça internacional, para Bull, seria da ordem de acontecimentos revolucionários e não fruto de continuidade e sedimentação.

\footnotetext{
${ }^{7}$ HURRELL. Foreword to the Third Edition: The Anarchical Society 25 Years on. In: BULL, Hedley. The Anarchical Society. A study of Order in World Politics. (Third Edition). New York: Columbia University Press, 2002.

8 Idem, viii.
} 
É a herança intelectual de Martin Wight, assumida por Bull, ${ }^{9}$ que aparece claramente, naquilo que difere o realismo, o liberalismo (então referido como racionalismo) e uma visão revolucionária da política internacional. Esta última é a que poderia contemplar o projeto de uma eventual ordem internacional justa, jamais uma perspectiva racional como a da Escola Inglesa. A perspectiva revolucionária da ordem, ou seja, a crença de que é possível e viável uma mudança radical no sentido de constituir-se, mais do que uma sociedade de Estados, uma comunidade de homens de âmbito universal, não está no cálculo de uma perspectiva teórica racional como a de Bull (2002). Mas quais seriam, então, os limites deste equilíbrio entre imperativos éticos e políticos internos a cada sociedade nacional e a constituição de uma sociedade internacional toleravelmente “ajustada”, sem hierarquias e ímpetos imperialistas?

\section{UMA JUSTIÇA INTERNACIONAL PARA QUEM?}

No vigoroso debate contemporâneo, em que autores como J. Rawls, ${ }^{10}$ Morris Ginsberg, ${ }^{11}$ Michael Walzer, ${ }^{12}$ entre outros, procuram redimensionar espectros “do que é justo" aplicável ao âmbito internacional, a filosofia moral está presente e cumpre um papel analítico fundamental. O fato é que são as mesmas transformações globais da virada do século que geraram instituições transnacionais, agências internacionais capazes de representar interesses multinacionais governamentais e não governamentais, que também levaram parte da literatura sobre justiça a procurar resgatar neste debate a possibilidade e a necessidade de se pensar em uma justiça internacional de caráter social.

Um elemento importante a ser destacado ao se refletir sobre justiça em um âmbito social é que a globalização da economia e as consequências da intensificação da interdependência global nos levariam a reconhecer mais um fator de complexidade para o tema da justiça internacional, segundo Álvaro de Vita. ${ }^{13} \mathrm{Na}$ medida em que a globalização pode ser vista como

\footnotetext{
${ }^{9}$ Ver histórica publicação de Bull em homenagem à Martin Wight, por ocasião de seu falecimento em 1976: Bull, H. "Martin Wight and the Theory of International Relations: The Second Martin Wight Memorial Lecture" British Journal of International Studies, Vol. 2 N. 2 (Jul. 1976), pp. 101-116.

${ }^{10}$ RAWLS, John. A Theory of Justice. Cambridge, Mass.: Harvard University Press, 1971.

${ }^{11}$ GINSBERG, Morris. On Justice in Society. London: Heinemann, 1965.

12 WALZER, Michael. Just and Unjust Wars.New York: Basic Books, Inc., 1977; WALTER, Michael. Spheres of Justice, New York: Basic Books, 1983.

${ }^{13}$ VITA, Álvaro de. A justiça igualitária e seus críticos. São Paulo: Martins Fontes, 2007; VITA, Álvaro de. O liberalismo igualitário. Sociedade democrática e justiça internacional. São Paulo: Martins Fontes, 2008.
} 
um processo impulsionador da desigualdade, elevar-se-ia o tema da desigualdade como um problema normativo e institucional central do século XXI. Da mesma forma que, no caso da justiça doméstica, o estudo da natureza da justiça no plano internacional poderia então ser dividido, para finalidades analíticas, em duas grandes áreas temáticas, segundo Vita. ${ }^{14}$ São elas os temas relativos à tolerância e os temas relativos à justiça distributiva.

A “tolerância” abrangeria os problemas de justiça política, seja nas esferas doméstica ou internacional. Neste contexto, perguntar-se-ia: como podemos viver juntos se discordamos sobre como devemos viver? Dada a diversidade de concepções do bem individual e coletivo e de tradições morais e religiosas, trata-se de saber se é e como é possível fundar a sociedade internacional em princípios análogos aos direitos liberais clássicos (os direitos civis) e aos do governo democrático ${ }^{15}$ Ainda segundo o autor, a outra área temática abrangeria a questão da pobreza e da desigualdade que levaria ao debate sobre a “justiça distributiva” para o campo internacional. Em outras palavras, o tema da justiça acaba por envolver a busca de mecanismos para uma reorganização do sistema mundial que fosse capaz de redistribuir as riquezas globais de modo mais equânime. Assim, uma teoria da justiça aplicada ao plano internacional deveria se traduzir pela capacidade de assegurar a dignidade humana, no seio da sociedade nacional e internacionalmente. Trata-se de uma perspectiva que, baseada em noções de direitos humanos, defende a irrelevância geográfica ou institucional em função do valor da igualdade.

$\mathrm{Na}$ prática, mais uma vez, torna-se inevitável a reflexão sobre os obstáculos da implementação dessa justiça internacional, baseado no sistema de Estados soberanos no qual a ordem internacional se encontra. Se por um lado, desde Kant, qualquer ideia de fundação de uma reguladora que se comparasse a um "Estado mundial" tem sido frequentemente rejeitada, alegando-se que tal entidade careceria de legitimidade e tenderia inevitavelmente ao despotismo. Por outro lado, como se pode defender então uma teoria única da justiça internacional sem se conceber uma realidade de centralização de poder, um Leviatã mundial ou uma utopia irrealizável? Este tem sido um dilema desafiador, mas que precisa ser compreendido dentro de marcos assumidamente liberais ou utópicos, para que não se confundam teses analíticas com teorias normativas.

Qualquer ideia de justiça internacional pressupõe a remoção de privilégios, discriminações e diferenças, veiculadas por reformas, seja pela via do direito ou da política. Ao

\footnotetext{
${ }^{14}$ VITA, Álvaro de. O liberalismo igualitário. Sociedade democrática e justiça internacional. São Paulo: Martins Fontes, 2008.

${ }^{15}$ Idem.
} 
final, qualquer ponderação sobre justiça é, antes de tudo, a consideração de que Estados não apenas competem estrategicamente para realizarem seus próprios interesses e expandir suas possibilidades, mas são capazes de transpor valores democráticos e liberais encontrados na política doméstica para o âmbito das relações internacionais. De fato, Estados estão na base da ordem internacional e a noção de justiça implicaria mais do que ordem ou mesmo espaços tópicos de compartilhamento de interesses.

Autores como David Miller ${ }^{16}$ não se mostram otimistas quanto ao aparecimento de uma sociedade justa onde não há uma comunidade de fato. Sobre a desconexão entre pobreza e desigualdade internacional, Miller considera que a justiça só existiria enquanto garantia de algum patamar mínimo definido em termos absolutos e especificado por um conjunto de direitos básicos, mais ou menos restritos. Por outro lado, a injustiça seria a privação de direitos básicos, possuindo assim pouca ligação com as desigualdades distributivas resultantes de arranjos internacionais e mais relação com arranjos domésticos de caráter políticos e governamental. Assim, como propõe Álvaro de Vita ao citar Miller em sua obra, ${ }^{17}$ a preocupação com a desigualdade internacional estaria fora da questão relativa a justiça e da responsabilidade de membros da sociedade internacional que se encontram em posições mais privilegiadas economicamente. Como não há uma estrutura institucional unificadora para as regras, o direito e as instituições nas relações internacionais, o compartilhamento de valores e a cooperação internacionais não são suficientes para se falar em uma "comunidade global."

O que está em questão, em última análise, é o confronto entre duas visões: aquela que enfatiza a participação do indivíduo no processo de construção tanto da sociedade internacional quanto da concepção de justiça internacional e aquela que considera a ordem internacional sob a perspectiva do individualismo dos Estados. A segunda visão não ignora necessariamente o valor da primeira, mas a considera utópica e revolucionária. Desde uma perspectiva realista, a ideia da justiça internacional se vê limitada pela interpretação de que não há sinais de profunda transformação do atual modelo de tomada de decisão pública e internacional considerando-se o que de fato ocorre na ação de organizações, regimes e formas de governança internacionais em que os Estados são os atores prevalentes. Estudos representam esforços importantes sobre o aumento da participação de atores não-estatais nos processos decisórios de organizações

\footnotetext{
${ }^{16}$ MILLER, David. Justice and Global Inequality. In: HURRELL, Andrew \& WOODS, N. (eds.), Inequality, Globalization, and World Politics, Oxford: Oxford University Press, 1999.

${ }^{17}$ VITA, Álvaro de. O liberalismo igualitário. Sociedade democrática e justiça internacional. São Paulo: Martins Fontes, 2008.
} 
internacionais, até mesmo considerando a importância de ativismos transnacionais e de networks. Mas como a literatura tem mostrado, esta forma de influência não se comprova como algo que se apresente como mecanismo substituto do poder os Estados e, sim, de resistência e/ou suporte a eles. Por fim, ainda é possível se colocar em questão se o ideal de democracia cosmopolita e de cidadania global oferece uma interpretação normativamente atraente da forma de justiça política a ser realizada no âmbito internacional. ${ }^{18}$

O principal argumento de Michael Walzer em Spheres of Justice (1983) é que a construção de uma teoria de justiça distributiva deve sempre ser relativa a valores da comunidade a que se destina, ou seja, a história e a cultura da comunidade serão sempre fatores relevantes no processo dessa construção. Assim, uma justiça social internacional, considerandose 0 argumento de Walzer, ${ }^{19}$ deve estar implicada no reconhecimento de valores sociais, construídos historicamente, entre os atores internacionais. Pode-se considerar que a identificação dos valores comuns ou de uma cultural global deveria estar na base da construção de uma noção de justiça, segundo a visão comunitarista. A perspectiva de que o fenômeno da globalização estaria gerando uma nova cultura global, especialmente do ponto de vista das ciências sociais ${ }^{20}$ procura dar suporte a uma tese de que a proliferação de atores e ações não estatais estaria sendo responsável pela emergência de novos valores. Neste contexto, a ação de atores não-estatais estaria gerando novos processos de negociação e expectativas sobre o papel de instituições internacionais governamentais e internacionais.

É preciso determinar de forma clara e evidente que esta é uma perspectiva otimista sobre o futuro comportamento dos atores políticos e, principalmente, dos indivíduos. 0 debate sobre "cultura global" ou "democracia cosmopolita" pertence a uma visão mais radical do que a crença no aperfeiçoamento da ordem internacional, pois neste caso é preciso uma verdadeira revolução nos mecanismos de interação e construção de uma ordem que seja substitutiva a existente. Em outras palavras, é preciso uma ordem que se sobreponha ao modelo de Estados e instituições internacionais tal como existem atualmente e se constitua a partir de relações entre indivíduos e comunidades, envolvendo povos de todo o mundo. Isto é o que se refere autores como David Held, ao designarem a constituição de uma "democracia cosmopolita": uma democracia global e única em substituição a diversos e diferentes modelos de democracia

\footnotetext{
${ }^{18}$ Idem.

${ }^{19}$ WALZER, Michael. Just and Unjust Wars.New York: Basic Books, Inc., 1977; WALTER, Michael. Spheres of Justice, New York: Basic Books, 1983.

${ }^{20}$ BOLI, John; THOMAS, George M., World Culture in the World Polity: A Century of International Nongovernmental Organization. American Sociological Review, n. 62, Issue 2, 1997, pp. 171-190.
} 
nacional. ${ }^{21}$ A origem da noção de 'cosmopolitismo' remonta a Grécia antiga, particularmente ao ideal estoico de que os seres humanos são racionais com direitos universais de cidadãos da 'Cosmópolis'. Tendo a noção de 'Cosmópolis' como inspiração, a “democracia cosmopolita” poderia se realizar na incorporação de um racionalismo universal em que os seres humanos iguais se comportassem enquanto iguais e constituíssem uma só comunidade política global.

Revisitado o pensamento de Bull sobre o tema da ordem e da justiça internacional, tornase interessante a verificação do debate contemporâneo sobre o tema, especialmente em seus aspectos revolucionários de teorias que pressupõem uma transformação da ordem anárquica internacional em uma ordem menos desigual. No entanto, cabe acrescentar que o argumento a favor do cosmopolitismo e contra a "parcialidade nacional" também deve ser enfrentado de modo mais embasado na história e nas efetivas experiências internacionais de cooperação e associações voluntárias caso pretenda se inserir no debate da política internacional. 0 argumento filosófico do "cosmopolitismo político" não é questionado pelos teóricos das relações internacionais mais do que sua viabilidade. Mesmo o senso de pertencimento a comunidades políticas nacionais e a importância prática das nacionalidades para o funcionamento das instituições dos Estados democráticos de direito, bem como da própria ordem internacional, não tem sido enfrentado rigorosamente pelas teses cosmopolitas. Seja pelo aspecto da identidade, seja pelo aspecto da segurança, as nacionalidades e o desejo de se pertencer a uma "comunidade imaginada"22 não tem mostrado sinais de superação por outro modelo de pertencimento global. Ainda que se reconheçam novas zonas de identidades sobrepostas, não tratadas neste artigo, não há sinais na história recente das Relações Internacionais de substituição ou aniquilação dos nacionalismos. Identidade continua a ser um tema problemático e não parece estar perto de desaparecer do universo do debate político, especialmente, da política internacional. Para além do debate normativo há também utilidades e funções de instituições políticas nacionais e princípios de organização dos Estados e da ordem internacional que não estão sendo avaliados pelas teses do cosmopolitismo.

Em suma, o tema da sociedade civil global pode ser visto como o mais significante avanço na conscientização de que existem identidades e interesses comuns compartilhados entre indivíduos pertencentes a diferentes nações, mas o rompimento com o modelo estatal em função

\footnotetext{
${ }^{21}$ HELD, David. Democracy and the Global Order. Stanford: Stanford University Press, 1995; HELD, David. Principles of Cosmopolitan Order. In: BROCK, G. e BRIGHOUSE, H. (orgs.). The Political Philosophy of Cosmopolitanism. Cambridge: Cambridge University Press, 2005, pp. 10-27.

${ }^{22}$ ANDERSON, Benedict. Imagined Communities. Reflections on the Origin and Spread of Nationalism. London/New York: Verso, 1991, p. 91
} 
da emergência de uma concepção de justiça que considere a interação de indivíduos se sobrepondo a dos Estados ainda é uma perspectiva revolucionária e utópica da ordem internacional, tal qual identificada por Bull.

\section{BULL: ORDEM VERSUS JUSTIÇA NA POLÍTICA INTERNACIONAL}

Retomando-se a contribuição de Bull, 'ordem' e ‘justiça' diferem exatamente porque a ordem pode ter apenas um sentido funcional e ser investigada como uma racionalidade ou uma lógica não-valorativa, mas efetiva. Ordem pressupõe o arranjo de coisas buscando determinado resultado, logo adquire dimensões objetivas. Por essa razão, ao dedicar o capítulo IV da "Sociedade Anárquica" ao tema da justiça, descreve um dos estudos mais cuidadosos e complexos sobre definições possíveis de justiça, sua aplicabilidade para a justiça internacional e a diferença de critérios normalmente utilizados segundo os atores em interação. A questão normativa sobre justiça está na base da distinção de Bull e os nuances por ele explorados parecem ser ainda os mesmos que o debate contemporâneo não conseguiu esgotar. Este consistiria no fato do uso do termo justiça ser considerado sob diferentes aspectos e valores poucas vezes explicitados ou considerados como dados a priori.

Sem desconsideração sobre a relevância do debate teórico contemporâneo sobre justiça internacional, o lugar de onde falam seus interlocutores, no entanto, deve ser levado em conta. Bull identifica quatro variações nas definições e usos de conceitos de justiça: "justiça geral” e “justiça particular”; “justiça substantiva” e “justiça formal”; “justiça aritmética” e “justiça proporcional”; “justiça comutativa” e "justiça distributiva”.

É geral qualquer definição de justiça que leve em conta acepções de moralidade, ou seja, quando se considera justa a "conduta virtuosa” (ação justa neste caso é vista como aquela moralmente correta). Justiça particular, em contrapartida, seria uma noção de justiça que considera a igualdade de direitos em termos de se construir a expectativa de uma "conduta correta". Nesta concepção, o exemplo dado por Bull é o das demandas por igualdade na distribuição ou aplicação de direitos, bem como pela reciprocidade que garanta igualdade no gozo de direitos e privilégios.

A segunda e mais conhecida distinção citada pelo autor é aquela entre justiça substantiva e justiça formal. A primeira noção se refere ao reconhecimento de regras com atribuição de direitos e a segunda à sua aplicabilidade (iguais condições de deveres e direitos 
entre atores em interação). Destaca Bull que na política internacional a demanda por justiça é geralmente pela justiça formal, no sentido de se esperar a aplicação das mesmas regras igualmente a todos os Estados. Exemplo que pode ser citado é o direito de não interferência nos assuntos internos de um Estado.

A questão da proporcionalidade, vista de perto, é complexa para o debate sobre a definição de justiça. Deve-se fazer justiça pela igualdade de direitos e deveres (que envolveria a justiça formal) ou pela finalidade, que poderia ferir a igualdade em nome de uma justiça substantiva? Aqui, de acordo com Bull, estaria em questão a terceira distinção por ele proposta: a distinção entre justiça aritmética e justiça proporcional. No debate sobre a justiça proporcional, defende-se que os direitos e deveres a serem distribuídos entre os atores devem ser diferentes em função dos objetivos. A quarta distinção pode ser entendida em conjunto com a terceira, pois a noção de justiça proporcional se afina com o conceito de justiça distributiva, que privilegia a deliberação do bem ou interesse comum sobre o procedimento igualitário. De outra forma, uma justiça aritmética que garanta igualdade de direitos, voltada por isso ao procedimento mais do que ao objetivo, é compatível com a noção de justiça comutativa.

$\mathrm{Na}$ política internacional a justiça distributiva é a mais discutida e seria alcançável a partir da transferência de recursos de países ricos para países pobres. Nela enfoca autores como Rawls e debates que enfrentam a relação entre pobreza e igualdade no âmbito das relações internacionais. Na prática, entretanto, a política internacional e sobretudo considerando-se os processos de conflito e cooperação entre Estados que possuem uma percepção rudimentar sobre "bem comum", o que se vê é o predomínio, principalmente, de princípios de uma justiça "comutativa".

As distinções conceituais devem servir, entretanto, sob relevante consideração dos atores que se encontram em interação na busca da realização do que é justo. Em outras palavras, paralelamente às distinções, considerando a concepção de justiça pertencente necessariamente à "categoria de ideias morais", ${ }^{23}$ de acordo com Bull, a definição pode variar em função dos sujeitos. De acordo com o autor são três as condições valorativas de justiça que se distinguem segundo os atores em interação: (i) "justiça internacional é entre Estados"; (ii) "justiça individual ou humana" se dá entre indivíduos e nações; (iii) "justiça mundial ou cosmopolita" se refere a uma sociedade cosmopolita sem distinções nacionalistas ou estatais. A solução para a

${ }^{23}$ BULL, Hedley. Sociedade Anárquica, São Paulo: Ed. Unb-IPRI, 2002, p.93. 
controvérsia conceitual, para Bull, está no fato de que conforme os atores envolvidos, variará a perspectiva do valor da justiça:

(i) Justiça internacional são regras morais que atribuem direitos e deveres aos Estados e às nações, que têm o direito de se organizarem em Estados. Justiça entre Estados nem sempre é uma justiça óbvia e simples de se compreender porque direitos podem ser conflitantes e indivíduos possuem objetivos diferentes de pessoas coletivas, bem como nações podem ter objetivos diversos e valores conflitantes com os Estados que as acolhem. Por exemplo, o direito à autodeterminação das nações pode ser conflituoso com a soberania dos Estados.

(ii) Justiça individual é como são entendidas as regras morais que atribuem direitos e deveres individualmente aos seres humanos. É a doutrina de direito natural dos homens que pode ser atribuída como um conjunto de princípios fundamentais do próprio direito internacional. ${ }^{24}$

(iii) Justiça mundial ou cosmopolita é como são entendidas regras morais que seriam certas e boas para todo o mundo; ou seja, para uma imaginária sociedade cosmopolita ou comunidade mundial. Note-se que essa noção de justiça como promoção do bem comum mundial é diferente da afirmação dos direitos e deveres individuais igualitários. O valor de um bem comum em escala mundial não se confunde com objetivos compartilhados ou valores comuns entre diferentes sociedade de Estados, mas com a concepção da fundação de uma só sociedade universal, que reuniria toda a humanidade.

Não apenas as definições variam, mas, de acordo com os agentes e atores levados em conta, concepções de justiça entram em conflito. Como exemplo, os direitos de alguns Estados podem entrar em conflito tanto com direitos de nações quanto com um suposto direito mundial que deveria incorporar o bem comum universal. Enfim, trata-se aqui do mais antigo dos debates sobre liberdade e igualdade - debate este que sempre escapou à uma só solução racional, pois revelam uma inescapável variedade de preferências e lógicas de entendimento sobre a política. No caso de Bull, o autor não pretende discutir a justiça mundial em termos de valores ou preferências, mas revela neste ponto de modo claro e evidente sua influência realista ao afirmar que "a ordem (social) em si é valiosa e precede outros objetivos, inclusive o da justiça". ${ }^{25}$

Distinguindo tipos ideais de justiça, Bull ${ }^{26}$ analisa as consequências da adoção da prioridade da justiça sobre a ordem. Para uma visão conservadora ou ortodoxa, a imposição de uma justiça mundial ameaçaria as raras áreas de consenso na política internacional. Por essa

\footnotetext{
${ }^{24}$ BULL, Hedley. Sociedade Anárquica, São Paulo: Ed. Unb-IPRI, 2002, pp.97-98

${ }^{25}$ Ibidem. p.114.

${ }^{26}$ Ibidem. p.110.
} 
razão, a ordem deve ser mínima e a justiça estaria fora de questão quando se trata de política internacional. Uma visão revolucionária defenderia, mesmo diante dos conflitos, a implementação de uma justiça mundial e necessária, ainda que provocasse desordem ou violência temporárias, por se fundamentar em um otimismo sobre o resultado do estabelecimento de uma ordem, não mais mínima, mas justa. Finalmente, para a visão liberal ou progressista, há o reconhecimento do conflito entre ordem e justiça, mas considera-se viável a interferência de modos brandos de conciliação, em que valores da justiça mundial possam ir sendo incorporados pelas regras do sistema da ordem internacional de modo gradual e progressivo. Assim, como princípios de direito individual começam a ser incorporados pelo direito internacional, também valores da justiça mundial poderiam - de forma não revolucionária - incorporar-se em um modelo de ordem internacional sem que se rompam as estruturas existentes. Essa última considerada uma matriz importante da política externa no Ocidente. ${ }^{27}$

O autor considera que existem obstáculos concretos à realização de uma "justiça mundial" nos moldes das teses do cosmopolitismo. O cenário internacional contemporâneo não revela um desenvolvimento de uma ordem ou sistema internacional em que os Estado estejam dispostos a abrir mão do controle dos mecanismos de governança ou de manutenção das regras do jogo da política internacional. Ao contrário, segundo Bull, a ordem internacional é preservada exatamente por meios que ferem sistematicamente os princípios mais básicos e mais amplamente aceitos da justiça internacional. Enfim, sua perspectiva liberal revelada através do tratamento deste tema traduz o espírito de Bull em sua obra mais caso ao tema da justiça. Isso se explica porque demandas por justiça fazem parte da promoção e manutenção da ordem, ${ }^{28}$ desde que incorporadas em algum regime que proporcione "mais ordem" à sociedade internacional. Em outras palavras, demandas por justiça podem fazer parte da ordem se não afetarem os fundamentos da sociedade anárquica.

\section{CONCLUSÃO}

Apesar da existência de compartilhamento de interesses e valores comuns, além de certa consciência sobre os limites de regras legais e morais no meio internacional, a noção de uma

\footnotetext{
27 BULL, Hedley. Sociedade Anárquica, São Paulo: Ed. Unb-IPRI, 2002, p.111.

28 Idem.
} 
justiça internacional não seria manifesta na ordem contemporânea, segundo Bull. ${ }^{29}$ Assim, ao tratar dos limites da justiça internacional, o autor deixa evidente sua concepção de sociedade internacional constituída em torno de práticas compartilhadas e entendimentos intersubjetivos construídos entre Estados, vistos como atores sociais ${ }^{30}$ que interagem sem que haja uma quebra de sua estrutura hierárquica para a constituição de uma comunidade mundial.

A conclusão é que não foi superada a relevância da contribuição de uma perspectiva racional que busca conciliar a prevalência da igualdade jurídica e soberania dos atores estatais com a possível ameaça da ordem. Da mesma forma que não foi esgotado o tema que, pela sua própria natureza, exige um debate teórico constante e interdisciplinar - para o qual esse artigo procurou contribuir. Procuramos destacar o quanto o debate sobre justiça, enquanto grande divisor de águas entre perspectivas utópicas e realistas é tema protagonista da principal obra de Bull, ${ }^{31}$ embora esse parece ser um de seus legados menos explorados. A consideração conceitual de justiça na obra de Bull é absolutamente complementar aos seus conceitos de ordem internacional e de sociedade internacional. A própria tensão entre ordem e justiça não deixou de ser um dos debates mais intensos e ricos da Escola Inglesa, ${ }^{32}$ do qual Bull é um dos principais expoentes e novas contribuições não cessam de surgir no campo das teorias das relações internacionais.

Finalmente, a perspectiva internacionalista de Bull se conecta com a emergência de uma "sociedade anárquica". Ou seja, o meio internacional possui traços de uma sociedade, mas, ao mesmo tempo, não possui uma centralização de valores nem uma regulação única capaz de desconstituir a condição hierárquica nacional ou anárquica internacional - o que equilibra e sustenta a relação entre os Estados soberanos e individualistas, logo sempre competidores.

\section{REFERÊNCIAS}

ANDERSON, Benedict. Imagined Communities. Reflections on the Origin and Spread of Nationalism. London/New York: Verso, 1991

BEITZ, Charles R. Political Theory and International Relations. Princeton, NJ: Princeton

\footnotetext{
${ }^{29}$ BULL, Hedley. Sociedade Anárquica, São Paulo: Ed. Unb-IPRI, 2002.

30 BULL, Hedley. Sociedade Anárquica, São Paulo: Ed. Unb-IPRI, 2002, pp. 9-10

31 BULL, Hedley. Sociedade Anárquica, São Paulo: Ed. Unb-IPRI, 2002.

32 VALENÇA, Marcelo. M. Política, emancipação e humanitarismo: uma leitura crítica da Escola Inglesa sobre a questão da intervenção humanitária. Contexto Internacional. v. 31, n. 2, 2009, pp. 319-320.
} 


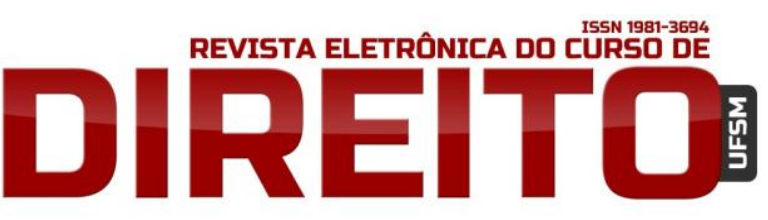

REFLEXÕES TEÓRICAS SOBRE JUSTIÇA INTERNACIONAL: REVISITANDO HEDLEY BULL

University Press, 1999.

BOLI, John; THOMAS, George M., World Culture in the World Polity: A Century of

International Non-governmental Organization. American Sociological Review, n. 62, Issue 2, 1997, pp. 171-190.

BULL, Hedley. Sociedade Anárquica, São Paulo: Ed. Unb-IPRI, 2002.

BULL, Hedley. Martin Wight and the Theory of International Relations: The Second Martin Wight Memorial Lecture. British Journal of International Studies, v. 2, n. 2, 1976, pp. 101-116.

GINSBERG, Morris. On Justice in Society. London: Heinemann, 1965.

HELD, David. Democracy and the Global Order. Stanford: Stanford University Press, 1995.

HELD, David. Principles of Cosmopolitan Order. In: BROCK, G. e BRIGHOUSE, H. (orgs.). The Political Philosophy of Cosmopolitanism. Cambridge: Cambridge University Press, 2005, pp. 1027.

HOBBES, Thomas. Do Cidadão. (tradução, apresentação e notas Renato Janine Ribeiro) São Paulo: Martins Fontes, 1992.

HOBBES, Thomas. Leviatã, Col. Os Pensadores. (trad. João Paulo Monteiro e Maria B. N. da Silva) São Paulo: ed. Abril Cultural, 1974.

HURRELL, Andrew. Foreword to the Third Edition: The Anarchical Society 25 Years on. In: BULL, Hedley. The Anarchical Society. A study of Order in World Politics. (Third Edition). New York: Columbia University Press, 2002.

KAPSTEIN, Ethan. Distributive Justice as an International Public Good. In: KAUL, Inge; GRUNBERG, Isabelle; STERN, Marc A. (eds). Global Public Goods, Oxford: UNDP-Oxford University Press, 1999, pp. 88-115.

LOCKE, John. Two Treatises of Government. The Cambridge Texts in the History of Political Thought. New York: Cambridge University Press (The Second Treatise), 2005.

MILLER, David. Justice and Global Inequality. In: HURRELL, Andrew \& WOODS, N. (eds.), Inequality, Globalization, and World Politics, Oxford: Oxford University Press, 1999.

OSIANDER, Andreas. Sovereignty, International Relations, and the Westphalian Myth. International Organization. n. 55, v. 2, 2001, p. 251-287.

PARIJS, Philippe Van. International Distributive Justice. In: GOODIN, Robert E.; PETTIT, Philip; POGGE, Thomas (orgs), A Companion to Contemporary Theory, vol. 2. Oxford: Blackwell, 2007, pp. 638-652.

POGGE, Thomas. Realizing Rawls. Ithaca, NY: Cornell University Press, 1989 
RAWLS, John. A Theory of Justice. Cambridge, Mass.: Harvard University Press, 1971.

ROUSSEAU, Jean-Jacques. O Contrato Social. Col. Os Pensadores. (trad. Lourdes Santos Machado), São Paulo: Nova Cultural, vol. 1, 1987.

VALENÇA, Marcelo. M. Política, emancipação e humanitarismo: uma leitura crítica da Escola Inglesa sobre a questão da intervenção humanitária. Contexto Internacional. v. 31, n. 2, 2009, pp. 319-351.

VILLA, Rafael \& TOSTES, Ana Paula. Democracia Cosmopolita versus Política Internacional. Lua Nova. v. 66, 2006, pp. 66-107.

VITA, Álvaro de. A justiça igualitária e seus críticos. São Paulo: Martins Fontes, 2007.

VITA, Álvaro de. O liberalismo igualitário. Sociedade democrática e justiça internacional. São Paulo: Martins Fontes, 2008.

WALZER, Michael. Just and Unjust Wars. New York: Basic Books, Inc., 1977.

WALZER, Michael. Spheres of Justice, New York: Basic Books, 1983.

Recebido em: 03/01/2016 / Revisões requeridas em: 10/04/2017 / Aprovado em: 15/04/2017 